\title{
A Study on The Fully Enclosed Housing Of Interior Permanent Magnet Synchronous Motor
}

\author{
Ho-Joon Lee and Kun-A Lee * \\ Professor, School of Social Safety System Engineering, Hankyoung National University, 327 Chungang-r \\ o,17579, Republic of Korea \\ *Corresponding author E-mail : kalee@hknu.ac.kr
}

Article History:Received:11 november 2020; Accepted: 27 December 2020; Published online: 05 April 2021

\begin{abstract}
Approximately 2.5 billion won can be saved every year by replacing existing induction motors, which are traction motors for urban railway vehicles, with permanent magnet motors. This paper presents a study on the structural design of a completely enclosed motor to commercialize an interior permanent-magnet synchronous motor (IPMSM) for the traction of urban railway vehicles. The proposed solution provides protection from an inflow of dust and magnetic powder into the rotor that can deteriorate the motor performance and cause burnout. In addition, unless it is a water-cooled or oil-cooled structure, cooling of an electric motor used in medium and large-sized equipment is not easily accomplished. However, completely enclosed motors are vulnerable to overheating; therefore, research into housing design is required to provide cooling. Additionally, the permissible current density through the stator winding must be considered in the design to prevent the occurrence of thermal demagnetization of permanent magnets. Furthermore, IPMSMs require a separate driver for operation and speed controls for a wide range of operating conditions such as rail traction. Thus, a study has been conducted on IPMSMs and other related driver and control technologies, and their suitability has been validated through performance tests. Keywords: Interior Permanent Magnet Synchronous Motor(IPMSM); Fully enclosed housing, Demagnetization, Current density, Railway traction motor.
\end{abstract}

\section{Introduction}

The importance of urban railways is increasing due to the rapidly increasing traffic demand in urban areas, the limited supply of road traffic facilities, and environmental problems of the earth. And recently, urban railroad vehicles are required to increase the efficiency and weight of the traction motor in order to maximize eco-friendliness and energy efficiency. Accordingly, when replacing the existing induction motor with a permanent magnet motor with excellent efficiency and power density and easy maintenance, it is possible to save about 2.5 billion won in electricity bill per year[1-5]. Unlike Japan, which has consistently applied fully enclosed permanent magnet synchronous motors to railroad cars since the introduction of the first massproduced electric car adopting the first permanent magnet synchronous motor in 2006, Korea's railway technology in the situation that there are no mass-produced electric cars driven by permanent magnet synchronous motors. In need of vitality. With the development of semiconductors and control technology, the design of traction motors for urban railway vehicles has achieved a breakthrough from DC motors to induction motors and entered the final phase of development. However, to maximize the eco-friendliness and energy efficiency, an interior permanent-magnet synchronous motor (IPMSM) is required owing to its high efficiency and light weight. The IPMSM requires a separate driver for operation and speed control to achieve a wide driving range for vehicle traction. Therefore, research on driver and control technology using the IPMSM is required. The designed IPMSM is validated by conducting performance tests.

\section{IPMSM design based on electro-magnetic field}

\subsection{Basic design of IPMSM}

The design specifications of the existing subway towing induction motor are as follows. Squirrel cage type three-phase induction motor, air-cooled type, the number of poles is 4 , the insulation grade is $\mathrm{H}$ class, the gear ratio is about $7: 1$, and the weight is about $800 \mathrm{~kg}$. And the ratings of the output power, voltage and current of the induction motor are shown in Table 1.

The specifications of the permanent magnet synchronous motor were determined based on the specifications of the existing induction motor. In the case of the existing induction motor, the rotational speed at continuous rating was 1950rpm, the gear ratio was 7.07 (99/14), and the wheel diameter was $820 \mathrm{~mm}$. As discussed above, the rotational speed of the synchronous motor at continuous rating is $2400 \mathrm{rpm}$, and the maximum torque of the synchronous motor is designed to be $835.6 \mathrm{Nm}$ or more. The voltage of the line was assumed to be $1,500 \mathrm{~V}$ DC. As the first method for basic model design, a design equation for a permanent magnet synchronous motor was derived using the magnetic equivalent circuit method. The motor size information could be obtained by creating a design program using the derived design equation and then inputting the motor specifications in the user input portion of the design program.

With the calculated motor dimensions, modeled as shown in Figure 1 using a design program. The combination of the number of poles and the number of slots is modeled as $1 / 6$ because it has periodicity in the

*Corresponding author:Kun-A Lee

Professor, School of Social Safety System Engineering, Hankyoung National University, 327 Chungang-r o, 17579, Republic of Korea . kalee@hknu.ac.kr 
form of a 6-pole 54 slot. In addition, some dimensions have changed while modeling with an open slot type stator. The thickness of the permanent magnet is $10 \mathrm{~mm}$, the width is $74 \mathrm{~mm}$, the outer diameter of the rotor is $260 \mathrm{~mm}$, and the outer diameter of the stator is $435 \mathrm{~mm}$. The stacking length of the rotor and stator is $220 \mathrm{~mm}$, the number of turns per phase is 45 turns, and the number of conductors per slot is 10 . The number of parallel circuits is 2 . Input current is 3 phase 220 Arms. The figures 2 below show the designed basic model and the result of the electromagnetic field characteristics of the motor obtained by the finite element analysis method.

Table1 Each rating of induction motor

\begin{tabular}{c|c|c}
\hline Contents & Continuous & Instantaneous \\
\hline Power [kW] & 200 & 220 \\
Line Voltage [V] & 1,100 & 1,100 \\
Phase Current [A] & 130 & 145 \\
RPM [rpm] & 1,950 & 1,945 \\
Frequency [Hz] & 66.5 & 66.5 \\
Efficiency [\%] & 92 & 92 \\
Power factor [\%] & 88 & 88 \\
\hline
\end{tabular}

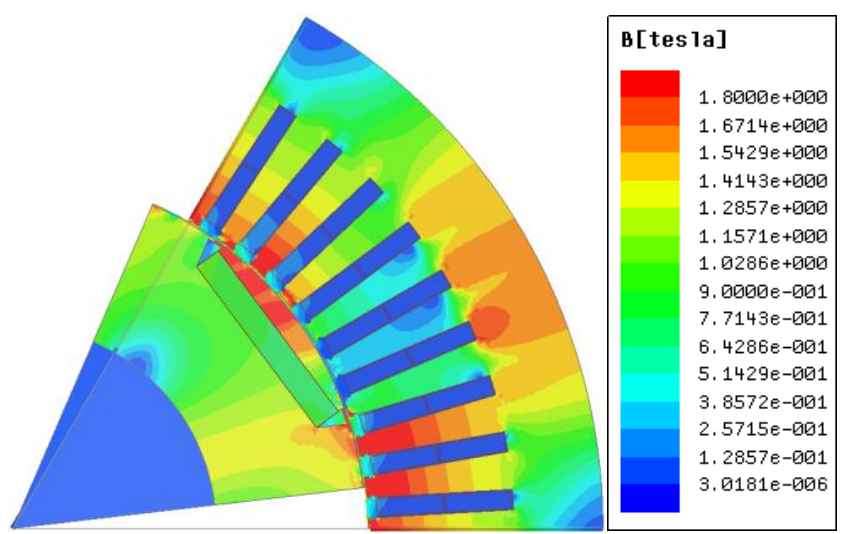

Figure 1 Magnetic flux density distribution of the basic design model (2400rpm, $\beta=40 \mathrm{deg}$ )
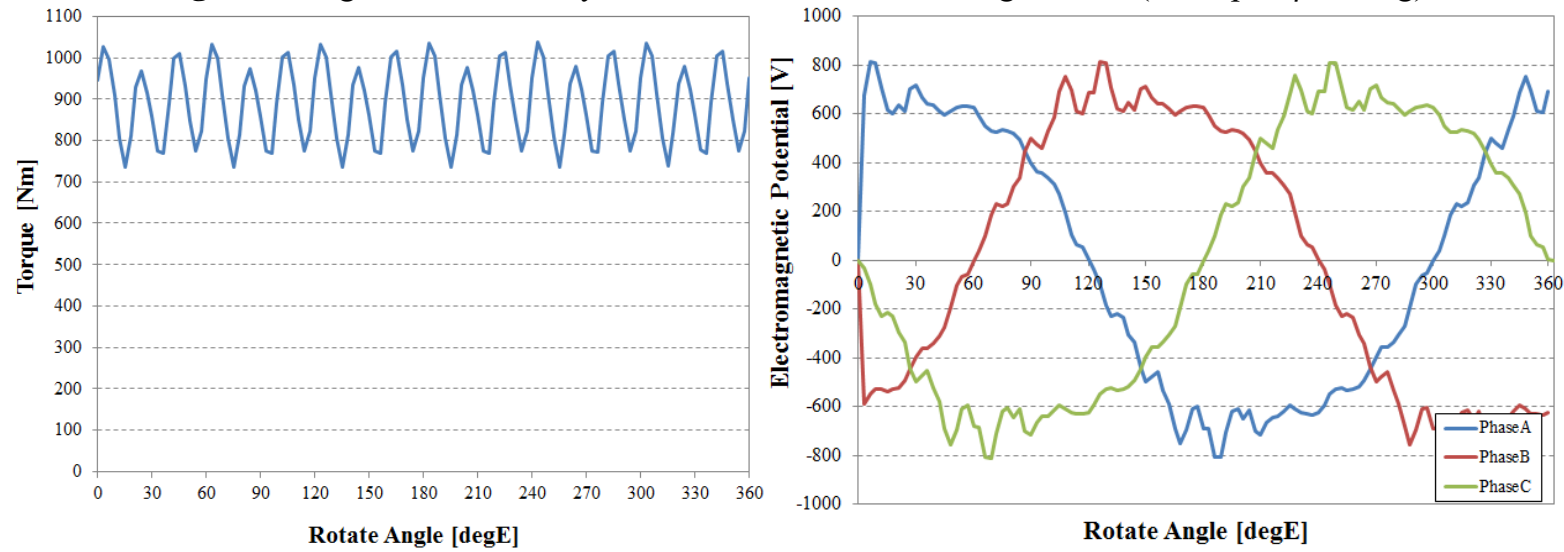

Figure 2 Average torque profile \& Electromagnetic voltage of the basic design model (2400rpm, $\beta=40 \mathrm{deg}$ )

\subsection{Optimal model of IPMSM}

The basic design model satisfies the specifications required as a traction motor for urban railway vehicles, but the torque ripple, which can be a source of electromagnetic noise and vibration, is relatively large, and the structural characteristics of the permanent magnet embedded in the rotor make it structurally robust[6-8]. I need to confirm. For this, the structural analysis was conducted as follows. To proceed with the structural analysis, first, only the rotor part was extracted from the basic design model and then changed to a three-dimensional shape. And after bonding only the upper surface of the permanent magnet to become the structurally weakest condition during rotation, the structural analysis was performed by setting the rotor to rotate at the maximum speed of the motor, which is $6000 \mathrm{rpm}$. The structural analysis, the safety factor was 0.25 , which was very low compared to the standard value of 1.5 , which means that there is a high possibility that permanent magnets will be scattered due to the structural failure. Therefore, it was inevitable to change the structure of the rotor permanent magnet while maintaining the existing characteristics. As a result of the third structural analysis, as shown in Figure 2.5, the safety factor was 1.62, which satisfies the standard of 1.5 or more. In order to solve the rigidity problem of a permanent magnet synchronous motor, it was concluded that it was necessary to design a 
rotor in the form of two bridges. And sensitivity analysis was performed to determine how much each design variable affects torque and torque ripple. When conducting the analysis, the rotation speed of the motor was set to $2400 \mathrm{rpm}$, the slot width was $7.6 \mathrm{~mm}$, the web width was $43 \mathrm{~mm}$, and the barrier angle was fixed at $13 \mathrm{deg}$. In addition, analysis was conducted on the three-segmented permanent magnet angle (Magnet Angle) and permanent magnet position (Magnet X-Position, Magnet Y-Position) for rotor stiffness. The optimal design model was modeled as shown in Figure 3 with the optimal size of the major design variables obtained through the sensitivity analysis.

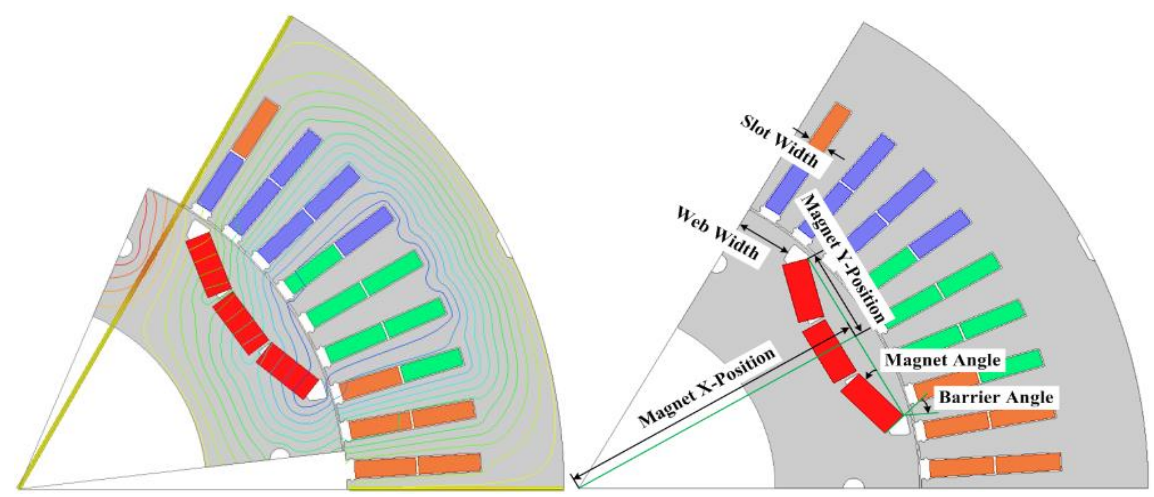

Figure 3 Optimized IPMSM Model and its Design Parameters

The proposed IPMSM model was designed to satisfy the existing requirements in induction motors used for towing urban railway vehicle. In particular, the rotor structure was designed with two bridges between the permanent magnets to reduce the torque ripple, which may cause electromagnetic noise and vibration, and to ensure the stability of the permanent magnets embedded in the rotor. A sensitivity analysis was performed based on the design variables, as shown in Fig. 1, to analyze their effects on the torque and torque ripples and derive an optimal model. A comparison of the power density between the existing induction motor and the IPMSM is shown in Table 1. The output from the induction motor was predicted by performing finite-element analysis and the output of the IPMSM was obtained from a performance evaluation test. The result showed that the power density of the IPMSM was $0.79 \mathrm{KW} / \mathrm{Kg}$, which was $75.6 \%$ greater than that of the existing induction motor.

\subsection{IPMSM design with completely enclosed enclosure}

Based on the designed optimal model, an IPMSM with a completely enclosed enclosure was studied considering its potential for commercialization [9-10]. An air-circulation path was secured in the rotor to enable a completely enclosed type. Circular holes were drilled in the rotor to increase the heat dissipation area of the steel core and facilitate air circulation. As shown in Figure. 5, it was designed to minimize the influence on the output torque while maintaining a safety factor of at least 1.8 at $3000 \mathrm{rpm}$. An air-circulation path was created to improve the circulation around the stator yoke. However, large circulation holes can cause a significant increase of the outer diameter of the motor, whereas smaller circulation holes can block heat circulation. Therefore, the air-circulation path was only applied to the rotor, as shown in Figure. 4.

The open type had enough cooling effect, so there was no need to worry about the temperature increase, but the fully closed type should consider the temperature increase. Therefore, it is necessary to examine the change in calorific value and cooling capacity. Existing induction motors have an efficiency of 94.8\% and IPMSM prototypes have an efficiency of $98.3 \%$, so the loss is reduced from $11.5 \mathrm{~kW}$ to $3.6 \mathrm{~kW}$. Since the loss is the amount of heat generated per hour, the amount of heat generated per hour in IPMSM is reduced by $1 / 3$ compared to the induction motor. In order to estimate how much the temperature rise will be when it is manufactured as a fully enclosed type without a cooling fan, all vents of the first starter were closed and a temperature rise test was conducted. The temperature rises during saturation became $230 \mathrm{~K}$. As a result of testing IPMSM without a ventilation fan, the temperature increased by $160 \mathrm{~K}$ in 1 hour, so the second initiator decided to cool by attaching a ventilation fan. The internal line circulates the air inside the machine, and at the same time, the outside line passes the air outside the machine through the ventilation path installed around the motor to increase the cooling effect. In addition, by making the directions of the internal and external air flows opposite to each other, the temperature gradient direction of the internal and external air flows along the partition wall in contact with the internal and external air is the same, thereby increasing the cooling efficiency.

In general, the stator winding current density was designed according to the cooling method. To reduce the heat generation, the current density should be designed such that it is lower than that of a semi-enclosed structure. Thus, it was lowered from $5.7 \mathrm{Arms} / \mathrm{mm} 2$ to $4.0 \mathrm{Arms} / \mathrm{mm} 2$. In the case of the semi-enclosed enclosures, the maximum temperature increased to approximately $140{ }^{\circ} \mathrm{C}$ in rated operation for $1 \mathrm{~h}$. Additional 
thermal demagnetization analyses were conducted to determine the risk of demagnetization of the permanent magnets at high temperature. With the assumption that the motor reaches the saturation temperature and the maximum current flows owing to a failure of the inverter, the magnetic flux density was set to its value at $180{ }^{\circ} \mathrm{C}$ and a current that was three times the rated current was applied to the winding. From the obtained results, it was confirmed that there were no adverse effects. It was determined that it would rise to about $270^{\circ} \mathrm{C}$ through mathematical analysis. And it was judged that the loss value generated by the motor would be proportional to the heat generation amount, and the current density was designed to be 4 Arms, which is 1.7 Arms lower than the primary starter designed with a current density of 5.7 Arms. As a result, the outermost angle of the electric motor was reduced from $435 \mathrm{~mm}$ to $430 \mathrm{~mm}$.
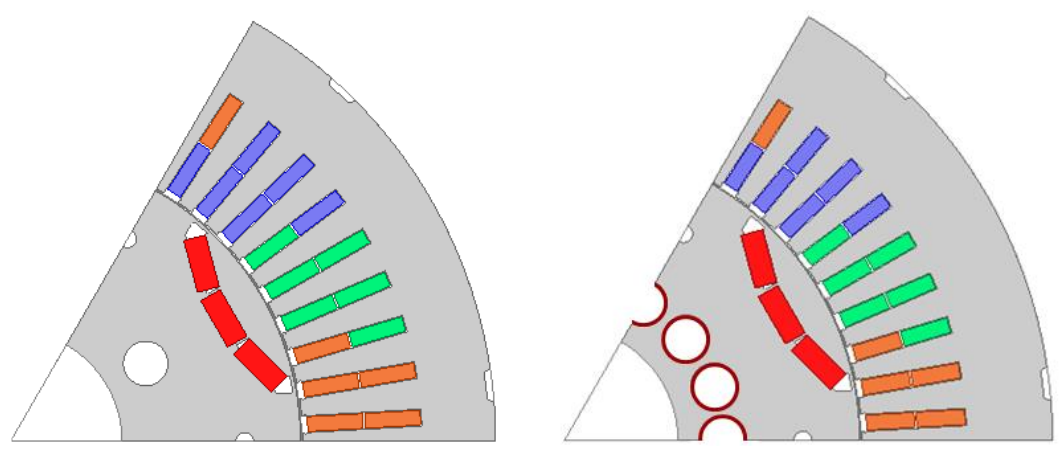

Figure 4 IPMSM Design with Enclosed Enclosure
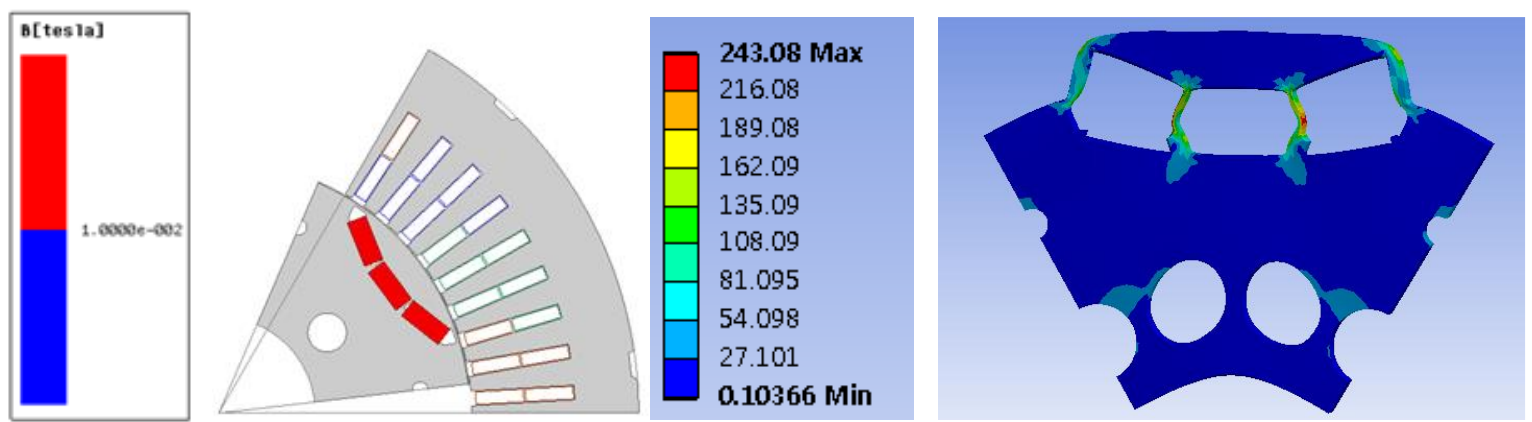

Figure 5 Demagnetization and Rotor Stress Results

\section{Results}

Table 2 shows the output of the induction motor is calculated through finite element analysis, and the output of the IPM motor is the result obtained through the performance evaluation test. As a result of the test, it was confirmed that the power density of IPMSM is $0.79 \mathrm{KW} / \mathrm{Kg}$, which is a $75.6 \%$ increase compared to the power density of the conventional induction motor with $0.79 \mathrm{KW} / \mathrm{Kg}$ and satisfies the target value of $20 \%$.

The primary and secondary initiators have rotors of the same size. An air circulation path was added here to reduce the weight of the motor and facilitate heat circulation. To lower the current density, the slot area of the stator was modified. Because of the use of copper wire, the rectangular structure was maintained, but the length of the slot was reduced by increasing the dot ratio, while the current density was decreased. The diameter of the motor was also reduced by $5 \mathrm{~mm}$, reducing the total mass of the motor. As a result, the power density increased by $50 \%$ compared to the actual vehicle applied traction induction motor.

Figure 6 shows the motor dynamo system and Table 3 shows the results of torque, power and efficiency performance tests at rated speed.

Table2 Power density of induction motor and IPMSM

\begin{tabular}{c|c|c}
\hline Contents & Induction Motor & IPMSM \\
\hline \hline Weight $[\mathrm{kg}]$ & 451.6 & 265.7 \\
Power $[\mathrm{W}]$ & 205.4 & 214.1 \\
Power Density $[\mathrm{kW} / \mathrm{kg}]$ & 0.45 & 0.79 \\
\hline
\end{tabular}

Table3 Performance of prototype of IPMSM 


\begin{tabular}{c|c|c}
\hline Contents & Induction Motor & IPMSM \\
\hline Weight $[\mathrm{kg}]$ & 451.6 & 265.7 \\
Power $[\mathrm{W}]$ & 205.4 & 214.1 \\
Power Density $[\mathrm{kW} / \mathrm{kg}]$ & 0.45 & 0.79 \\
\hline
\end{tabular}

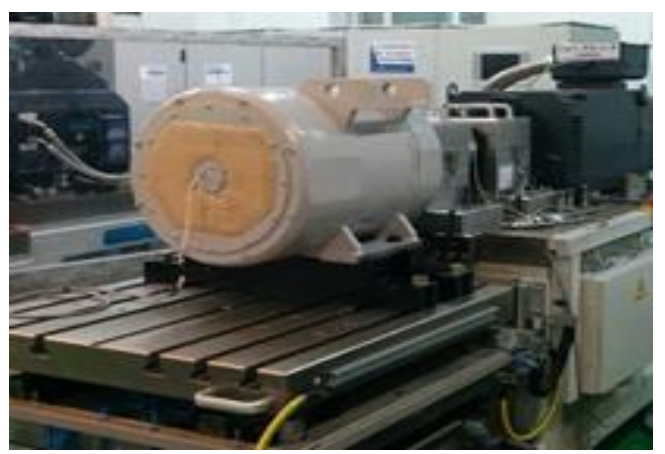

Figure 6 Prototype and dynamo systems

\section{Conclusions}

This paper presents an IPMSM design that provides a higher power density than that provided by existing induction motors, based on research on traction motors for urban railway vehicles. Furthermore, instead of the general semi-enclosed enclosures, a completely enclosed enclosure was implemented considering the potential for commercialization. To reduce the heat generation in the enclosed enclosures, an air-circulation path was secured in the rotor and the current density was minimized to the maximum possible extent. Thermal analysis and rotor stiffness analysis were performed, and the results were verified through testing.

IPM motor design technology is a technology that can be applied not only to urban railway vehicles, but also to light rail or high-speed rail, and when the IPM motor is adopted as a traction motor for light rail or high-speed rail, the design technology can be usefully utilized. In addition, if the IPM motor is applied as a traction motor for railway vehicles, it is expected that the IPM motor manufacturing industry and the power converter manufacturing industry will become active. As a result, urban rail operation and maintenance costs can be reduced by improving the efficiency of traction motors, and it will play a role in enhancing technological competitiveness in the global railroad market by securing core device technologies for next-generation rail vehicles.

\section{References}

1. Park CB, Lee HW, Lee BS and Lee J. A study on the iron-loss reduction of Interior Permanent Magnet Synchronous Motor for Railway Transit. Transportation Electrification Conference and Expo: IEEE; 2012. June; $1-4$.

2. Shengxue L, Yifa S. Efficiency Optimization of IPMSM for Urban Rail Traction Based on switching frequency optimization control. Chinese Control Conference: IEEE; 2011. July; 1997-2001.

3. Nguyen QH, Schuster J, Jorg RS. Optimal Control of an Electrically Excited Synchronous Motor used as Traction Drive. ICPE: The Korean Institute of Power Electronics 2015. June; 2789-2795.

4. Heredi AL, Calleja C, Lertxundi A, Aranburu A. Stator current and power factor optimization in an IPMSM for railway traction application. Power Electronics and Applications: IEEE; 2011. Sept; $1-10$.

5. Lee HW, Park CH, Lee BS. Performance comparison of the railway traction IPM motors between concentrated winding and distributed winding. Transportation Electrification Conference and EXPO: IEEE 2012. June; $1-4$.

6. Dylan B, Russ M. Design of Liquid Cooled IPM Motor for High Torque Density Applications. International Electric Machines \& Drives Conference IEEE; 2019. May; 2152-2159.

7. Yamazaki K, Fukushima Y, Sato M. Loss Analysis of Permanent-Magnet Motors With Concentrated Windings - Variation of Magnet Eddy-Current Loss Due to Stator and Rotor Shapes. Transactions on Industry Applications: IEEE 2009. August; 45: 1334-1342.

8. Gillon F, Brochet P. "Shape optimization of a permanent magnet motor using the Experimental design method. Transactions on Magnetics: IEEE; 1999. May; 35: 1278-1281.

9. KEPCO report, High efficiency magnetic materials and their applications. Taejon, Korea, 2011.

10. Azar Z, Wu LJ, Evans Z, Zhu Q. Influence of rotor configuration on iron and magnet losses of fractionalslot IPM machines. International Conference on Power Electronics, Machines and Drives: IET; 2010; 1-5. 